\title{
AS RAÍZES CIENTÍFICAS DA TOPOLOGIA ESTRUTURAL DE LACAN
}

\section{Vitor Hugo Couto Triska; Marta Regina de LeÃo D'Agord}

\author{
Vitor Hugo Couto \\ Triska \\ Universidade Federal \\ do Rio Grande do Sul \\ (UFRGS), Doutor pelo \\ Programa de Pós- \\ Graduação em \\ Psicologia Social e \\ Institucional, Porto \\ Alegre/RS, Brasil. \\ Marta Regina de Leão \\ D'Agord \\ Universidade Federal \\ do Rio Grande do Sul \\ (UFRGS), Professora do \\ Programa de Pós- \\ Graduação em \\ Psicanálise: Clínica e \\ Cultura, Porto \\ Alegre/RS, Brasil.
}

RESUMO: Este artigo investiga as consequências da adoção da concepção de ciência moderna de Koyré, caracterizada pela matematização do real, na obra de Lacan. Uma delas é a invenção da topologia estrutural que, muito embora enraizada na linguística e na matemática, ultrapassa o domínio científico ao qual pertencem essas disciplinas. Para tanto, as noções de estrutura, letra e real serão apropriadas e ressignificadas por Lacan.

Palavras-chave: ciência, topologia, estrutura, real.

Abstract: The scientific roots of Lacan's structural topology. This article investigates the consequences of the adoption of Koyrés modern science conception, caractherized by the mathematization of the real, in the work of Lacan. One of them is the invention of structural topology. Even though its origins are refered to linguistic and mathematics, it reaches beyond their scientific domain. Therefore, the notions of structure, letter and real are going to be used by Lacan in his own ways.

Keywords: science, topology, structure, real.

DOI - http://dx.doi.org/10.1590/S1516-14982018002008

Todo o conteúdo deste periódico, exceto onde estiver identificado, está licenciado sob uma Licença Creative Commons (cc by 4.0) 
Vitor Hugo Couto Triska \& Marta Regina de Leão D’Agord

Em Mais, ainda (1972-73/1985), Lacan comenta a relação da psicanálise com duas disciplinas, a saber,

Elinguística e matemática. A referência a ambas está presente em toda a obra lacaniana, mas ficará claro que o teorizar psicanalítico não pode ser reduzido às práticas dessas disciplinas - ele as excede e busca seus próprios caminhos. Talvez as críticas que apontam a incompatibilidade entre as práticas próprias a esses campos e a maneira como Lacan as utiliza, publicadas sob a forma de acusações de impostura intelectual (SOKAL; BRICMONT, 2001), falhem em considerar justamente isso: o uso que Lacan faz da linguística, matemática etc., não busca empregar seus métodos de maneira fiel, isto é, tais quais praticados dentro desses campos. Ao considerar os comentários de Glynos e Stavrakakis (2002) sobre o assunto, o psicanalista Paulo Rona entende que

não são os matemáticos, ou Sokal como seu arauto, quem devem ratificar a pertinência de um saber supostamente estranho à psicanálise, senão ela mesma naquilo que as matemáticas interessariam aos problemas enfrentados na experiência clínica. (RONA, 2002, p. 18)

A partir de Lacan, a psicanálise, muito embora absorva amplamente saberes e métodos de outras disciplinas, não tem a pretensão de se adaptar a nenhuma epistemologia já estabelecida para ter sua autenticidade reconhecida. $O$ que Paul-Laurent Assoun afirma sobre o freudismo valerá também para o lacanismo: "A psicanálise não tem necessidade de epistemologia; ela a possui; e é a isso que se chama de freudismo: basta objetivá-lo novamente" (1993, p. 19). Ao reunir e discutir com notável profundidade as epistemologias que influenciaram Freud de maneira determinante, o autor encontra o limite desta determinação: há algo chamado freudismo, uma identidade epistemológica não redutível aos domínios que Ihe são, no entanto, imprescindíveis. O mesmo vale para Lacan, inclusive no que diz respeito a seu retorno a Freud: Lacan não abraça todo freudismo, não pode ser reduzido a ele, tampouco a Koyré, Lévi-Strauss, Jakobson, Kojève, Bourbaki etc. Segundo Foucault, em O que é um autor? (1969/2006), o retorno a instauradores de discursividade, como Marx e Freud, redescobre lacunas e falhas em seus textos, modificando-os. Isto significa que, ao contrário de um retorno a, por exemplo, Galileu, onde a história da mecânica poderia ser revisada, mas não a mecânica em si, um retorno a Freud modifica a própria psicanálise. Neste artigo, porém, nos limitaremos a investigar o retorno a Freud a partir da relação de Lacan com o discurso científico, a matemática e a linguística.

Em Mais, ainda, primeiramente encontramos o anuncio de ruptura com Jakobson e a linguística:

(...) será preciso, para deixar a Jakobson seu domínio reservado, forjar alguma outra palavra. Chamarei a isto de linguisteria. (...) Meu dizer que o inconsciente é estruturado como uma linguagem não é do campo da linguística. (LACAN, 1972-73/1985, p. 25)

Logo após, Lacan afirma que a linguística pertence ao discurso científico: "A linguística, no campo em que se produz a fala, não é algo espontâneo. Um discurso a sustém, que é o discurso científico" (ibidem, p. 42). Em $O$ Aturdito, texto contemporâneo a Mais, ainda, Lacan insiste que a referência pela qual situa o inconsciente "escapa à linguística, posto que, como ciência, ela não tem o que fazer com o pareser (parêtre)" (1972/2003, p. 491). Se é inconcebível que a psicanálise venha de outro campo senão o da ciência (LACAN, 1966/1998b, p 232), é preciso que ela a exceda para que possa fazer algo com o saber inconsciente. Sobre a diferenciação em relação à matemática e a todo discurso científico, Lacan ainda sustenta: "O truque analítico não será matemático. É mesmo por isso que o discurso da análise se distingue do discurso científico" (197273/1985, p. 159).

Primeiras conclusões: Lacan inclui tanto a matemática quanto a linguística no discurso científico. Ao distinguir a psicanálise de ambas, também a distingue da ciência. Curiosamente, porém, a referência a esses campos não se extingue por isso. Muito pelo contrário, Lacan vai utilizá-los amplamente, chegando a afirmar que nada parece “(...) melhor constituir o horizonte do discurso analítico do que esse emprego que se faz da 
letra em matemática" (1972-73/1985, p. 61). Destaca-se assim um movimento de aproximação e diferenciação, onde a teorização psicanalítica dialoga com a ciência sem, contudo, fundir-se a ela. Sobre a formalização matemática enquanto via de acesso ao real, Lacan ainda afirma que "o real só poderia se inscrever por um impasse da formalização. Aí é que eu acreditei poder desenhar seu modelo a partir da formalização matemática (...)” (1972-73/1985, p. 125). A estrutura da linguagem, ou, como veremos, o seu real, não será mais do domínio da linguística, mas da formalização lógico-matemática, o que, contudo, não faz da psicanálise uma matemática.

Não haveria nada senão uma grande contradição se Lacan tão somente afirmasse a distinção entre sua psicanálise e esses campos enquanto fizesse uso de seus saberes e métodos. Com efeito, Lacan propõe novas noções a partir da apropriação, pela psicanálise, da matemática e da linguística. A linguisteria citada acima, ao mesmo tempo aproximação e ruptura, é um exemplo.

Uma importante invenção lacaniana se dará a partir do reconhecimento de uma espécie de interseção entre matemática e linguística que Ihes é, paradoxalmente, exterior. Ela será própria à psicanálise e formará um domínio estranho tanto à linguística quanto à matemática, aliás, ao discurso científico. Lacan a nomeia topologia estrutural ${ }^{1}$ (1972/2003), uma retomada da estrutura da linguística a partir da letra e da topologia matemática. Demonstra-se assim a "estrita equivalência entre topologia e estrutura” (1972-73/1985, p. 17), uma vez que "o significante (...) deve ser estruturado em termos topológicos" (ibidem, p. 29). O significante, pura diferença, configura um espaço não-euclidiano, topológico. A equiparação entre topologia e estrutura não é óbvia e Lacan não se dedicou a fundamentá-la completamente. Um exemplo de tese dedicada a fundamentar essa aproximação é a do supracitado Rona, que o faz a partir da teoria dos conjuntos. O autor demonstra que a topologia, antes de ser uma ciência dos espaços, tem seu fundamento na teoria dos conjuntos, afinal, "apresentar ou não apresentar uma topologia é uma propriedade de uma coleção de conjuntos" (RONA, 2012, p. 47). Seria, portanto, legítimo o uso não metafórico que Lacan faz das expressões "lógica do significante" e "topologia do significante", pois "é matematicamente que uma topologia e suas transformações se apresentam nas operações com a linguagem, com que a psicanálise conta em seu trabalho" (ibidem, p. 219-20). Encontrar - ou construir - o fundamento da união da topologia com a estrutura não será, entretanto, nossa tarefa neste escrito. Buscamos antes traçar as raízes da topologia estrutural na matematização do real proposta pelo discurso científico.

Se o inconsciente é estruturado como uma linguagem, e se esse dito não é do campo da linguística, mas da linguisteria, será preciso situar o sentido do termo estrutura. Lacan busca formalizar o que chama de "inércia da linguagem" a partir do uso da letra (também matematização ou literalização), e é a isso que chamará de estrutura (1972-73/1985, p. 150) ou ainda cadeia:

(...) desse termo estrutura, os outros fazem dele o que querem, mas eu, o que faço notar é isto - a dita linguagem comporta uma inércia considerável, o que se vê ao se comparar seu funcionamento com os signos que chamamos de matemáticos, matemas, unicamente pelo fato de eles se transmitirem integralmente. (ibidem, p. 152)

A estrutura, ou cadeia, identifica-se à inércia da linguagem, o que retorna ao mesmo lugar e do qual as letras matemáticas, compondo matemas, podem apreender algo. A estrutura é igualmente equiparada ao “impasse lógico" e ao "real que vem à luz na linguagem" ${ }^{2}$ (1972/2003, p. 477). Enquanto um impossível

\footnotetext{
${ }^{1}$ Conforme abordamos em A topologia estrutural de Lacan, publicado em Psicologia Clínica, v. 25, p. 145-161, 2013. Disponível em: <http://www.scielo.br/scielo.php?script=sci_arttext\&pid=S0103-56652013000100010>. Acesso em: 02 jun. 2015.

${ }^{2}$ Conforme apresentamos em Da ciência do Real à escrita do Real. In: SANTOS, T. C.; SANTIAGO, J.; MARTELLO, A. (Org.). Os corpos falantes e a normatividade do super social. 1. ed. Rio de Janeiro: Cia. de Freud, 2014. p. 171-198.
} 
secretado pela linguagem, a estrutura em Lacan se afastará da ideia de harmonia. Ela não terá nenhuma relação com a "boa forma" - termo que faz referência à compreensão pré-moderna do movimento dos planetas em círculos perfeitos. Por isso, Lacan não considera que Copérnico tenha promovido com o heliocentrismo uma revolução, conferindo esta à descoberta da elipse de Kepler (1972-73/1985, p. 59). Se Freud identifica a psicanálise a um golpe no narcisismo do homem comparável ao heliocentrismo e ao darwinismo, Lacan considerará a descoberta do movimento elíptico dos planetas, enquanto ataque à boa forma circular, como uma das balizas da ciência moderna e, por isso, condição à psicanálise. A estrutura, portanto, não se presta a ser uma nova forma, mais "exata" ou aperfeiçoada do que a antiga boa forma. Ela será antes a impossibilidade, o real que denuncia a falha da boa forma. As fórmulas da sexuação em Mais, ainda são um exemplo do impasse através da formalização matemática. $O$ real é demonstrado pela impossibilidade de estabelecer uma relação (rapport) ou harmonia sexual entre o homem e a mulher, representados em suas respectivas posições a partir de letras da álgebra lacaniana.

"Matematizar o real" caracteriza a ciência moderna tal qual concebida por Koyré e absorvida por Lacan. O psicanalista não apenas aceita essa concepção de ciência como, de certa forma, a pratica. Novamente, devemos reconhecer uma possível contradição, na medida em que Lacan exclui explicitamente a psicanálise do campo da ciência ao mesmo tempo em que toma para si seu gesto de matematização do real. Os trechos de Mais, ainda citados acima já contêm as afirmações que diferenciam a psicanálise do discurso científico. Por outro lado, vimos que Lacan coloca a psicanálise como oriunda da ciência, isto é, sua possibilidade está atrelada ao aparecimento do discurso científico. Poderemos desenvolver essas questões analisando a função da obra de Alexandre Koyré em Lacan:

(...) o discurso analítico pode fazer semblante de alguma coisa que seria ciência. Pois, enfim, desse seria ciência vocês estão muito pouco conscientes, embora certamente tenham algumas referências. Vocês sabem, eu as coloquei aí porque acreditava que era um bom momento para fazer vocês repararem na história. Vocês sabem que houve um momento onde pudemos, não sem fundamento, nos premiarmos com essa segurança de que o discurso científico havia sido fundado sobre o ponto de virada galileano. Parece-me que insisti suficientemente aí para supor que pelo menos alguns de vocês tenham ido às fontes, lá onde isso se nota: a obra de Alexandre Koyré. (LACAN, 1972-73/1975, p. 76, tradução nossa)

Organizando a lógica da fala de Lacan, destacam-se três sentenças: a) há um momento na história no qual o discurso científico foi fundado, b) esse momento é o "ponto de virada galileano", e c) é à obra de Koyré que Lacan faz referência para afirmá-lo. Lacan adota o que Milner (1995) chama de "corte maior", uma ruptura histórica no campo do conhecimento entre a era moderna (presença da ciência) e o período que a antecede: "Mas o que é preciso ver é a que ponto isso é um passo, um passo verdadeiramente subversivo, do ponto de vista do que se intitulou conhecimento" (LACAN, 13/03/73, tradução nossa) ${ }^{3}$. Isto significa dizer que não há maneiras não-científicas de conhecer, que o que os discursos pré-científicos produziram não foi conhecimento sobre o real: “(...) nada houve senão fantasia quanto ao conhecimento, até o advento da ciência mais moderna" (LACAN, 1972-73/1985, p. 172). O filósofo Slavoj Zizek também comenta a relação de Lacan com a ciência moderna:

Lacan rompe com o historicismo dos Estudos Culturais: para ele, a ciência moderna resolutamente NÃO é uma das "narrativas" em princípio comparáveis a outros modos de "mapeamento cognitivo" - a ciência moderna toca o real de uma maneira totalmente ausente nos discursos pré-modernos. (ZIZEK, 2002, p. 298, tradução nossa)

É uma leitura discutível do ponto de vista histórico. Dick Teresi, em As descobertas perdidas, defende a presença de métodos e conhecimentos propriamente científicos em épocas e civilizações amplamente menosprezadas pelos historiadores da ciência. $O$ autor refuta a versão de que a ciência moderna, cujas raízes

${ }^{3}$ Trecho ausente na edição brasileira de Mais, ainda, traduzido da versão de staferla.free.fr. 
estariam em solo grego, ficou, durante a idade Média até a Renascença, apenas "guardada" pelos árabes como simples escribas, tradutores e zeladores, sem prática científica própria (TERESI, 2008, p. 12). Para tanto, Teresi reúne inúmeras provas de atividades e descobertas científicas - com ênfase especial às matemáticas por parte de povos não-europeus anteriores à Renascença. O autor justifica o papel crucial da matemática na ciência:

Farady escreveu todos os resultados de seus experimentos em inglês simples. Mas nunca afirmou que "a natureza fala inglês". Apesar de a matemática talvez não ser a língua da natureza, é certamente a língua da ciência. (...) Se vamos dizer que as culturas não-europeias tinham ciência muito antes que os europeus lhe exportassem esse produto, devemos provar que elas tinham matemática (TERESI, 2008, p. 31).

E é a isso que boa parte de As descobertas perdidas será dedicada. Após extensa revisão bibliográfica, Teresi é levado a afirmar que "a nova matemática da Revolução Copernicana surgiu primeiro nas mentes islâmicas, e não nas europeias" (2008, p. 11). Além da necessidade da aplicação da matemática em forma de cálculos e medições para fins práticos, os árabes teriam também se interessado por questões abstratas, pela matemática pura (ibidem, p. 77). Isto significa dizer que as conclusões às quais Lacan chega a partir de Koyré são falsas? Houve conhecimento científico antes do corte maior?

Buscando na própria obra de Koyré as noções às quais Lacan faz referência nas sentenças que destacamos anteriormente, veremos o filósofo defender que "a história não opera através de saltos bruscos" e que "as divisões nítidas em períodos e épocas só existem nos manuais escolares", afinal, "desde que se comece a examinar as coisas um pouco mais de perto, desaparecem as fronteiras que se acreditava perceber anteriormente" (KOYRÉ, 2011, p. 7). Koyré não está afirmando, porém, que toda baliza de descontinuidade histórica pode ser relativizada quando suficientemente analisada. É preciso não abusar do argumento da continuidade histórica, pois "as mudanças imperceptíveis em curto espaço de tempo engendram, a longo prazo, uma diversidade muito nítida" (idem). Deixando mais claro o seu pensamento, ele afasta apenas "divisões categóricas e radicais" incompatíveis com a complexidade da "história da evolução espiritual da humanidade" (ibidem, p. 8). Finalmente - e fornecendo fundamento para o corte maior de Milner -, Koyré complementa que, apesar de que os limites cronológicos sejam vagos e superpostos, "não obstante, a periodização não é inteiramente artificial" (idem), afinal, de um ponto de vista mais amplo, "as distinções se apresentam bastante nítidas e os homens de uma mesma época têm muito em comum" (idem). Nossa conclusão: a ruptura que Lacan encontra em Koyré é antes lógica do que cronológica. Seu interesse será situar a psicanálise em relação ao discurso científico e o laço social que lhe é correlato. Para tais fins, discutir a questão histórica em pormenores é irrelevante e basta a Lacan considerar já estabelecido o discurso científico como condição ao aparecimento da psicanálise.

A segunda sentença de Lacan trata Galileu como um "ponto de virada". Segundo Koyré:

(...) a maneira pela qual Galileu concebe um método científico correto implica uma predominância da razão sobre a simples experiência, a substituição de uma realidade empiricamente conhecida por modelos ideais (matemáticos), a primazia da teoria sobre os fatos. (...) um método que utiliza linguagem matemática (geométrica) para formular indagações à natureza e para interpretar as respostas que ela dá. (KOYRÉ, 2011, p. 77)

Trata-se da matemática (mais especificamente da geometria) como a linguagem própria da natureza. No mundo moderno, pós-Galileu, as impressões imediatas, mesmo que observações relativamente sistematizadas, terão que ceder lugar aos dados resultantes das investigações matemáticas da natureza. Por mais que não haja um momento historicamente bem definido que garanta homegeneidade aos períodos anterior e posterior a Galileu, o ponto de virada galileano define como a ciência de ali em diante deve proceder: 
Vitor Hugo Couto Triska \& Marta Regina de Leão D’Agord

Galileu sabe que a experiência - ou se me posso permitir o emprego da palavra latina experimentum, para justamente situá-la em oposição à experiência comum, à experiência que não passa de observação -, que o experimentum é preparado, que o experimentum é uma pergunta feita à natureza, uma pergunta feita numa linguagem muito especial, na linguagem geométrica e matemática. Sabe que não basta observar o que se passa, o que se apresenta normalmente e naturalmente aos nossos olhos; sabe que é preciso saber formular a pergunta e, além disso, saber decifrar e compreender a resposta, ou seja, aplicar ao experimentum as leis estritas da medida e da interpretação matemática. (KOYRÉ, 2011, p. 52)

Essas breves das passagens de Koyré parecem suficientes para esclarecer o que Lacan faz referência nas sentenças destacadas. A decisão pela referência a Koyré, e não a qualquer outra concepção de ciência moderna, entretanto, resta não explanada. Não buscaremos aqui as possíveis razões biográficas da opção de Lacan, pois não há motivos para fazê-lo. Podemos, contudo, colher as consequências de tal escolha.

Koyré entende que o discurso científico se inaugura pela representação simbólica do real, sua matematização. Segundo o filósofo, a "matematização do real, que é o trabalho próprio do astrônomo (...), começa com a decisão de descobrir, sob a aparência desordenada, uma ordem inteligível" (KOYRÉ, 2011, p. 85). Já obtivemos aqui um traço da topologia estrutural em Lacan: uma ordem apreendida por letras. Mas a qual real o filósofo da ciência se refere? O real natural, o da física. Trata-se da substituição dos objetos do mundo por símbolos, letras, que permitem investigar o real de maneira ao mesmo tempo matemática e empírica, mesmo na ausência desses objetos ${ }^{4}$. Lacan também utiliza a letra para matematizar o real, mas qual?

(...) um real que nada tem a ver com o que o conhecimento tradicional suportou e que não é o que ele crê realidade, mas sim fantasia [fantasme]. O real, eu diria, é o mistério do corpo falante, é o mistério do inconsciente. (LACAN, 1972-73/1985, p. 178)

É justamente o fato de poder atingir o real que justifica a apropriação lacaniana do gesto que, segundo Koyré, inaugura a ciência moderna: "Só a matematização atinge um real - e é nisto que ela é compatível com nosso discurso, o discurso analítico (...)" (KOYRÉ, 1972-73/1985, p. 178). O real, porém, é outro, ele "nada tem a ver" (idem). Em Lacan, ele será como um núcleo duro que resiste à simbolização, um impossível que a letra toca e circunscreve sem apreender numa totalidade. A psicanálise lacaniana usa métodos pertencentes ao discurso científico a seu modo, ou seja, sem reduzir-se a suas epistemologias, para investigar e delimitar seus próprios objetos - como o saber inconsciente e o real que, por sua vez, são estranhos à ciência. $\mathrm{O}$ uso das letras é identificado como idiossincrático ao discurso científico e, mais especificamente, à lógica-matemática. Lacan refuta que esse uso seja chamado, pelo menos em psicanálise, de metalinguagem, pois o considera tão somente uma redução de material:

(...) todo discurso científico sobre a língua se apresenta por uma redução de seu material. (...) Redução do material quer dizer que a lógica começa na data precisa da história em que alguns elementos da linguagem, tidos como funcionando em sua sintaxe natural, são substituídos por uma simples letra por alguém que entende do riscado. E isso inaugura a lógica. É a partir do momento em que vocês introduzem um $A$ e um $B$ no se isto, logo aquilo que a lógica começa. É somente a partir daí que vocês podem formular, sobre o uso desse $A$ e desse $B$, um certo número de axiomas e de leis dedutivas que merecerão o título de articulações metalingüísticas, ou, se preferirem, paralinguísticas. (LACAN, 1968-69/2008, p. 34)

Se, para Lacan, a algebrização é o gesto científico fundamental para a matematização do real, e se, em Koyré, esse gesto é devido a Galileu, encontraremos outra discordância em Teresi: "Galileu nunca escreveu $\mathrm{d}=\mathrm{At}{ }^{2}$. Era considerado um grande matemático, mas não dominava a álgebra". Segundo o autor, o que o antigo

\footnotetext{
${ }^{4}$ A teoria da relatividade de Einstein, por exemplo, previu pelo menos dois fenômenos antes que pudessem ser testados: a deflexão da luz (os campos gravitacionais também agem sobre a luz, ou seja, os raios de luz são curvos) e a relatividade do tempo (o tempo não é absoluto e pode passar mais rápido ou mais devagar de acordo com o campo gravitacional onde o observador se encontra).
} 
físico estabelece é que "[O universo] está escrito na linguagem da matemática, e seus caracteres são triângulos, círculos e outras figuras geométricas" (TERESI, 2008, p. 61). A linguagem matemática de Galileu é, antes, geométrica (triângulos, círculos etc.) do que algébrica e a transcrição de suas descobertas para a linguagem algébrica ocultaria os seus esquemas mentais originais. Novamente, parece ser uma "minúcia" diante da qual Lacan é indiferente. Se a algebrização ou transcrição em fórmulas dos esquemas galileanos ocultam ou distorcem as particularidades das descobertas do físico, isto pouco importa. É como se a formalização fosse desde sempre o verdadeiro cerne da geometria galileana, afinal, é através dela que se manifestam as leis que a ordenam.

A formalização não é outra coisa senão a substituição, a um número qualquer de uns, disso que se chama uma letra. (...) qualquer que seja o número de uns que vocês coloquem sob cada uma dessas letras, vocês estão submetidos a um certo número de leis, leis de grupo, adição, multiplicação etc. (LACAN, 1972-73/1985, p. 177)

Em oposição a Koyré, Teresi entende que a lição deixada por Galileu é a prevalência do experimento sobre a teoria e, portanto, o célebre florentino teria, sim, realizado a experiência sobre a torre de Pisa em 1589. E mais: não apenas para provar que a aceleração gravitacional independe da massa do objeto, mas para provar que é preciso experimentar para conhecer a natureza (TERESI, 2008, p. 50). O Galileu de Teresi "pôs a matemática abaixo do experimento", afinal, "a matemática era uma linguagem apropriada para descrever os resultados de uma experiência, mas era preciso fazer a experiência", pois esta segue servindo à física moderna como o seu "alicerce" (ibidem, p. 190). Não podendo aprofundar o sentido do termo experiência em Teresi e Koyré para estabelecer um denominador comum que permita uma discussão, será o caso de apenas ressaltar uma diferença fundamental: para Koyré, o que Galileu demonstra é a primazia da teoria e mesmo o experimento é uma pergunta previamente elaborada por um raciocínio:

A boa física é feita a priori. A teoria precede o fato. A experiência é inútil porque, antes de toda experiência, já possuímos o conhecimento que buscamos. As leis fundamentais do movimento e do repouso, leis que determinam o comportamento espacial e temporal dos corpos materiais, são leis da natureza matemática (KOYRÉ, 2011, p. 212)

Já que não discutiremos a questão dos diferentes sentidos de experiência galileana, basta ver em Teresi a possibilidade de uma outra versão da história da ciência que sirva como um contraste que destaque as particularidades daquela acolhida por Lacan. Conforme já anunciado, também não interessa aos fins deste artigo investigar as razões da escolha de Lacan por Koyré - o seu sentido só será revelado pelo reconhecimento de suas consequências. E uma consequência que propomos é a seguinte: Lacan, como o Galileu de Koyré, não experimenta sem uma pergunta, o que no contexto da psicanálise significa que não faz clínica sem teoria. Até aqui não há nenhuma novidade, afinal, é próprio da psicanálise - e Freud o testemunha - que uma teoria crie uma prática clínica e que os eventos colhidos nessa prática sejam interpretados à luz da teoria, modificando-a quando preciso. Foi preciso antes conhecer o Édipo de Sofócles para só depois supô-lo como complexo inconsciente. Em uma comparação oportuna com a relação de Newton com suas hipóteses, Lacan afirma:

Mas para constatar isto, o que permite eliminar a hipótese, foi mesmo preciso que primeiro ele a fizesse, essa hipótese. (...) O inconsciente, eu não entro nele, não mais do que Newton, sem hipótese. (1972-73/1985, p. 194)

Jean-Marie Vaysse, em L'inconscient des modernes (1999), propõe a psicanálise em continuidade com o pensamento filosófico moderno, buscando demonstrar neste as condições do aparecimento daquela. Ainda que o inconsciente freudiano apareça como uma subversão no campo do saber, o autor nega que ele tenha vindo de lugar algum ou que seja uma novidade pura extraída da clínica. Bertrand Ogilvie, por sua vez, em 
Vitor Hugo Couto Triska \& Marta Regina de Leão D’Agord

Lacan: la formation du concept du sujet $(1987$, p. 7), entende que as questões colocadas por Lacan não são oriundas da psicanálise, isto é, de Freud, mas antes do contexto da psiquiatria e da filosofia de sua época, sendo reencontradas em Freud num segundo momento. Embora o desenvolvimento dessas questões primeiras tenha se dado no encontro com a psicanálise, o autor entende que não é daí que elas partem. 0 ponto comum que destacamos de Ogilvie e Vaysse é a pré-existência de um pensamento ou, nas palavras de Lacan, hipótese ao evento da descoberta ou criação do conceito. Mas a particularidade de Lacan, o seu matematizar o real, vai mais além: ele pode interrogar o inconsciente através da topologia estrutural. Como fazem os físicos teóricos e os matemáticos na prática da matemática pura, Lacan encontra saberes de maneira abstrata. Para isso, teve que fazer uma hipótese análoga à de Galileu: a matemática está para a natureza assim como a topologia estrutural está para a estrutura da linguagem. Teria Lacan chegado à topologia estrutural por uma necessidade clínica ou pela via de seu interesse científico?

Assim como em De um discurso que não fosse semblante (LACAN, 1971/2009), em O Aturdito a lógica é elevada pelo discurso psicanalítico a "sua potência extrema", ao estatuto de "ciência do real" (LACAN, 1972/2003, p. 449). Explicitado que a estrutura da linguagem não mais será um campo cuja abordagem é exclusiva da linguística estruturalista, Lacan se autorizará a buscar apoio na lógica-matemática e na topologia, constituindo o que podemos chamar de topológica ${ }^{5}$. É pelo jogo da escrita matemática (já tomada por Lacan num sentido mais amplo, não exatamente obediente à matemática) que o discurso psicanalítico se orientará para "tirar o que se pode tirar quanto à função da linguagem (...)" (1972-73/1985, p. 66).

A necessidade de forjar novas palavras (linguisteria, topologia estrutural etc.) para descrever sua prática é justificável: Lacan busca seus caminhos próprios. Quando afirma que "minha topologia não é de uma substância que situe além do real aquilo que motiva uma prática. Não é teoria" (1972/2003, p. 479), onde enfatizamos "minha topologia", inclusive rechaça que se pense nela como uma teoria que motiva uma prática. Ele não busca "exteriorizar esse real em padrões", o que seria reencontrar outra boa forma, mas demonstrálo diretamente em sua impossibilidade pelos impasses da formalização: "A topologia não foi 'feita para nos guiar' na estrutura. Ela é a estrutura - como retroação da ordem de cadeia em que consiste a linguagem" (ibidem, p. 485). Se a topologia não é teoria que orienta uma prática e tampouco é feita para nos guiar na estrutura, ou seja, ela é a estrutura, reforçamos a hipótese de que Lacan propõe uma homologia entre a topologia estrutural e a estrutura real do inconsciente. Aquilo que se descobre numa é homólogo ao que se pode descobrir na outra. Assim, justifica-se o extenso uso dos nós borromeanos, por exemplo, em numerosas lições onde Lacan os trabalha sem fazer referências aos conceitos psicanalíticos, sem buscar correspondências entres eles. Quando maneja insistentemente os nós, ele está encontrando o próprio tecido estrutural, conhecendo suas leis e impossibilidades, e não novas imagens para os termos psicanalíticos já conhecidos.

Embora algo complexa, a relação de Lacan com a ciência moderna e suas disciplinas, como a matemática e a linguística, é discernível, assim como o é a busca de uma topologia estrutural enquanto via epistemológica própria à psicanálise. 0 psicanalista, no entanto, não estabelecerá primeiramente o fundamento dessa via para só depois praticá-la. Esse fundamento restará inacabado. Devemos reconhecer, então, tanto a importância de juntar as referências que objetivam o que é próprio ao lacanismo - como Assoun faz com Freud -, quanto a necessidade de praticar a matematização do real da psicanálise. Apenas esclarecer o que resta nebuloso na obra de Lacan, ou seja, estabelecer uma epistemologia que indique métodos os quais a psicanálise deve obedecer, talvez sirva justamente para sua estagnação. Os fundamentos devem ser ao mesmo tempo sólidos, para apontar caminhos para a produção de saberes, e maleáveis, para permitir que esses novos saberes mantenham os próprios fundamentos em discussão.

${ }^{5}$ Termo criado e trabalhado em A topológica da verdade. aSEPHallus (online), v. IV, p. 1, 2009. Disponível em: <http://www.isepol.com/asephallus/numero_07/artigo_01_port.html>. Acesso em: 02 jun. 2015. 
Recebido em: 13 de outubro de 2015. Aprovado em: 7 de janeiro de 2016.

\section{REFERÊNCIAS}

ASSOUN, P.-L. Introdução à epistemologia freudiana. Rio de Janeiro: Imago, 1993.

D'AGORD, M. R. L.; TRISKA, V. H. C. Da ciência do Real à escrita do Real. In: SANTOS, T. C. ; SANTIAGO, J.; MARTELLO, A. (orgs.). Os corpos falantes e a normatividade do super social. 1. ed. Rio de Janeiro: Cia. de Freud, 2014, p. 171-198.

FOUCAULT, M. O que é um autor? (1969) Trad. António F. Cascais e Eduardo Cordeiro. 6. ed. Lisboa: Nova Vega, 2006.

GLYNOS, J.; STAVRAKAKIS, Y. Postures and impostures: on Lacan's style and use of mathematical science. In: . (orgs.) Lacan and Science. Karnac Books Ltd: London, 2002.

KOYRÉ, A. Estudos de história do pensamento científico. 3. ed. Rio de Janeiro: Forense, 2011.

LACAN, J. Ciência e verdade (1966). In: Escritos. Rio de Janeiro: J. Zahar, 1998a. P. 869-892. seminário, 18).

De um discurso que não fosse semblante (1971). Rio de Janeiro: Jorge Zahar, 2009. (O De um Outro ao outro (1968-1969). Rio de Janeiro: Jorge Zahar, 2008. (O seminário, 16).

Do sujeito enfim em questão (1966). In: . Escritos. Rio de Janeiro: J. Zahar, 1998b. P. 229-237.

Encore (1972-73). Disponível em: <staferla.free.fr>. Acesso em: 21 jun. 2015.

Encore (1972-1973). Paris: Seuil, 1975. (Le Séminaire, 20).

Mais, ainda (1972-1973). Rio de Janeiro: Jorge Zahar, 1985. (O Seminário, 20).

.O Aturdito (1972). In:

Outros escritos. Rio de Janeiro: J. Zahar, 2003. P. 448-497.

MILNER, Jean.-Claude. L'Oeuvre claire: Lacan, la science, la philosophie. Paris: Seuil, 1995.

OGILVIE, B. Lacan: la formation du concept du sujet (1932-1949). Paris: Presses Universitaires de France, 1987.

RONA, P. O significante, o conjunto e o número: a topologia na psicanálise de Jacques Lacan. São Paulo: Annablume, 2012

SOKAL, A., BRICMONT, J. Imposturas intelectuais. Trad. Max Altman. Rio de Janeiro: Record, 2001.

TERESI, D. As descobertas perdidas: as raízes antigas da ciência moderna, dos babilônios aos mais. Trad. Rosaura Eichenberg. São Paulo: Companhia das Letras, 2008.

TRISKA, V. H. C., D'AGORD, M. R. L. A topologia estrutural de Lacan. Psicologia Clínica, v. 25, 2013, p. 145-161. Disponível em: <http://www.scielo.br/scielo.php?script=sci_arttext\&pid=S010356652013000100010> Acesso em: 02 jun. 2015.

A topológica da verdade. aSEPHallus (online), v. IV, 2009, p. 1. Disponível em: <http://www.isepol.com/asephallus/numero_07/artigo_01_port.html>. Acesso em: 02 jun. 2015.

VAYSSE, J.-M. (1999) L'inconscient des modernes: essais sur l'origine métaphysique de la psychanalyse. Paris: Éditions Gallimard, 1999.

ZIZEK, S. Lacan between cultural studies and cognitivism. In: GLYNOS, J., STAVRAKAKIS, Y. (orgs.) Lacan and Science. London, Karnac Books, 2002.

Vitor Hugo Couto Triska

vhtriska@gmail.com

Marta Regina de Leão D'Agord

marta.dagord@ufrgs.br 